\title{
'||||||||||||||||||||||||||||||||||||||||||||||||||||||||||||||||||.
}

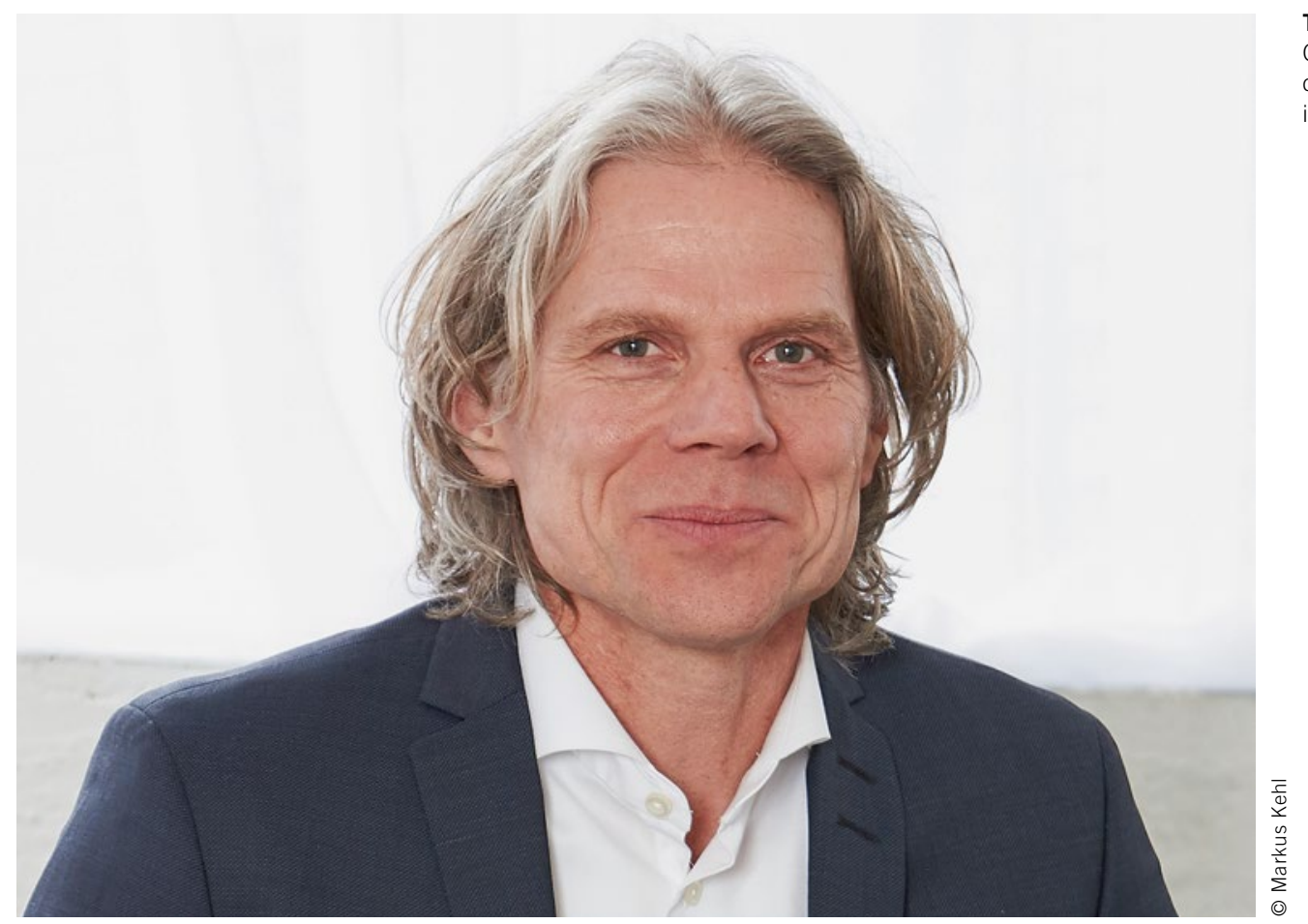

Thomas Korn

Gründer und CEO

der Keyou $\mathrm{GmbH}$

in Unterschleißheim

\section{Der Wasserstoffmotor kommt}

In diesen Tagen über die Evolution des Verbrennungsmotors zu schreiben, fällt angesichts der Corona-Pandemie gar nicht so leicht. Oder müssen wir vielleicht sogar genau jetzt über die Zeit nach Corona sprechen? Die Diskussionen über Klimaschutz, Energiewende und alternative Antriebstechnologien wieder aufnehmen? Gerade heute, wo manch einer die Pandemie politisiert und eine Aufweichung der strengen $\mathrm{CO}_{2}$-Ziele fordert?

Elektromotoren, Hybrid- und Wasserstofftechnologien, synthetische Kraftstoffe - um die weltweiten $\mathrm{CO}_{2}$-Ziele im Mobilitätssektor zu erreichen, werden verschiedene Alternativen diskutiert. Die Herausforderung besteht darin, Technologien zu entwickeln, die einfach und schnell in Masse produziert und aufgrund eines hohen Kundennutzens erfolgreich verkauft werden können. Und weil immer noch ein Großteil der produzierten Fahrzeuge mit Verbrennungsmotoren ausgestattet wird, sollte der Verbrennungsmotor selbst zum entscheidenden Baustein werden, um effektiven Klimaschutz zu betreiben. Dies hat auch die Politik erkannt: Die EU klassifiziert Fahrzeuge mit Verbrennungsmotoren als Zero Emission, wenn diese weniger als $1 \mathrm{~g} \mathrm{CO}_{2} / \mathrm{kWh}$ ausstoßen. Die gute Nachricht: Das ist möglich - mit modernen Wasserstoffverbrennungsmotoren!

Für diese Antriebsform spricht einiges, speziell im Nutzfahrzeugsektor. Neueste Wasserstoffmotoren können gewohnte Reichweiten abbilden. Die Betankungszeiten bewegen sich in üblichen Größenordnungen. Zudem sind sie absolut alltags- tauglich - ein wichtiges Kaufargument für den Endkunden. Hinzu kommt die gute $\mathrm{CO}_{2}$-Bilanz im Lebenszyklus dieser Motoren. Verbraucher kaufen heute schließlich nicht nur gern Bioprodukte, sie erwarten zunehmend, dass diese auch klimaneutral ausgeliefert werden.

Gute Argumente gibt es auch für Motoren- und Fahrzeughersteller. Sie können - ebenso wie die Zulieferunternehmen auf vorhandene Produktionsinfrastrukturen oder qualifiziertes Personal zugreifen. Investitionen halten sich damit in Grenzen, millionenschwere Ausgaben entfallen. Hinzu kommt, dass Hersteller mithilfe des emissionsfreien Wasserstoffmotors die strengen $\mathrm{CO}_{2}$-Flottengrenzwerte erfüllen und Strafzahlungen vermeiden können. Technologie, Ökologie und Ökonomie gehen hier eine wirklich sinnvolle Verbindung ein.

Bleibt das Argument von Skeptikern, der Wasserstoffmotor sei nicht effizient, sein Verbrauch zu hoch. Stimmt das? In Stadtbussen und -Lkw kann ein kosteneffizienter PFI-Motor, kombiniert mit einem P2-Hybrid, den Verbrauch von Brennstoffzellen-Fahrzeugen übertreffen. Im Fernverkehr mit hohen Volllastanteilen wird der robuste $\mathrm{H}_{2}$-DI-Motor mit hoher Leistungsdichte Verbräuche von effizienten Dieselmotoren unterbieten und den höchsten Kundennutzen bieten. Mangelnde Effizienz sieht anders aus.

Damit bleibt wohl nicht die Frage, ob der Wasserstoffmotor kommt, sondern lediglich, wann er kommt. 